\title{
Lo tangible y lo intangible. Fragmentos de memoria en el paisaje minero: el caso de la mina de Amiantos en Chipre
}

SELECCIÓN IX SEMINARIO INTERNACIONAL DE INVESTIGACIÓN EN URBANISMO Barcelona \& Bogotá, jun 2017.

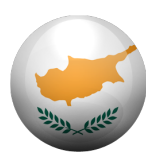

\section{Andri Tsiouti}

Master in Architectural Engineering (National Technical University of Athens). Estudiante del Master en Estudios Avanzados en Arquitectura (Universitat Politècnica de Catalunya) en Barcelona, España. Arquitecta. Nicosia [Nicosia] Chipre. <andritsiouti@hotmail.com>

Colaboradores / Orientadores:

Joaquín Sabaté Bel, Pere Joan Revellat Mira, \& Paula Orduña (directores de la tesina en curso). https://upcommons.upc.edu/bitstream/handle/2117/108337/131BCN_TsioutiAndri.pdf?sequence=1\&isAllowed=y

\section{Resumen}

Los paisajes mineros, al ser testimonio de la actividad humana vinculada con la explotación de los recursos minerales, presentan, frecuentemente, características patrimoniales. Las huellas del pasado acumuladas en dichos lugares, ya sean tangibles o intangibles, despiertan un creciente interés sobre la preservación y revaloración de los mismos. En este trabajo se estudia la mina de Amiantos, en la isla de Chipre, que por los efectos nocivos sobre el medio natural y a la salud humana provoca rechazo y abandono. A través de un análisis de su evolución e identificando sus elementos constitutivos, se pretende redescubrir la identidad de este territorio, un hilo conductor que pueda recoser el relato de su pasado mirando hacia un nuevo futuro.

\section{Palabras clave}

Paisajes mineros. Mina de Amiantos. Patrimonio minero. Memoria colectiva.

\section{The tangible and the intangible. Memory fragments at the mining landscape: the case of the Amiantos mine in Cyprus}

\begin{abstract}
Mining landscapes, for being testimony of the human activity related to the exploitation of mineral resources, they frequently present heritage features. The traces of the past concentrated in such places, whether tangible or intangible, generate an increasing interest on their preservation and revaluation. In this work it is studied the mine of Amiantos, in the island of Cyprus, which due to its adverse impacts on the environment and human health causes rejection and abandonment. Through an analysis of its evolution and identifying its constitutive elements, it is aimed to rediscover the identity of this territory, a guiding thread that could recover the story of its past looking towards a new future.
\end{abstract}

\section{Keywords}

Mining landscapes. Amiantos. Mining heritage. Collective memory. 


\section{Introducción}

Los paisajes de la minería, vinculados con la explotación de recursos minerales, acogen, a menudo, un variopinto conjunto de evidencias de un pasado que perduran en el espacio y el tiempo. Estos lugares acumulan características que, les aportan una cierta heterogeneidad y conflictividad, derivadas tanto de la alta transformación del medio como por sus extensiones económicas, sociales y culturales. Por ende, aunque afectan la memoria física y el legado de pueblos que han ido evolucionando extrayendo materiales de sus entrañas, implican a la vez una cierta conflictividad derivada de la valoración de la actividad minera como industria explotadora de los trabajadores, nociva para el medio ambiente y destructora del paisaje (Marchán et al., 2013). Sin embargo, esta identidad polifacética y su reconocimiento como parte de la historia de una comunidad, por una parte, y la capacidad de acoger nuevas actividades vinculadas al desarrollo y el bienestar, por la otra, despierta una creciente atención hacia estos "paisajes de trabajo" (Sabaté, 2005), que ha motivado diversas iniciativas para su preservación y reactivación.

La mina de Amiantos, abandonada desde 1988, representa un período de ochenta años de historia de la actividad minera chipriota y la industrialización de la isla. Por la explotación intensiva del amianto desempeñó un papel significativo en la prosperidad socio-económica del país y, en particular, para la periferia montañosa de Troodos. Quince mil personas trabajaron y vivieron allí con sus familias, construyendo una sociedad estrechamente vinculada a la actividad extractiva. Después del cierre de la mina y debido a las graves repercusiones sobre el medio natural causadas por las explotaciones, se puso en marcha el proyecto medioambiental más ambicioso y costoso de los últimos años en Chipre: el Plan de Restauración del paisaje de Amiantos, destinado a la recuperación del suelo contaminado, la reforestación y revegetación del terreno, que sigue en marcha a día de hoy (Tsintides, 2013). El paisaje del entorno minero se ha mejorado sensiblemente; sin embargo, las obras realizadas y programadas se limitan a la recuperación ambiental, mientras que los valores patrimoniales quedan en el olvido. Por ende, tanto los vestigios tangibles, muebles e inmuebles, como los intangibles representados por la memoria de la gente de Amiantos, que en su conjunto constituyen la identidad del lugar, siguen amenazados por el olvido, el deterioro y su desaparición con el paso del tiempo.

No obstante, durante los últimos años aparece un cierto interés sobre Amiantos expresado por varios agentes, públicos y privados, a través de artículos, documentales, libros, páginas web, además de la redacción de un master plan orientativo para el futuro aprovechamiento de la zona. Aun así, estas iniciativas continúan aisladas y sin implicar una visión integral del territorio, sino limitada a reflexiones incompletas y superficiales. Partiendo de esta problemática, en el presente artículo se procura demostrar que frente al rechazo de la mina por el daño que ha provocado, sus recursos tangibles e intangibles tienen un notable valor para sus antiguos trabajadores y vecinos, con capacidad para reconstruir e interpretar su identidad. Por ende se pretende reconstruir la memoria del paisaje minero mediante una identificación minuciosa y la clasificación de sus elementos de identidad que, permitan entretejer un relato de la historia de Amiantos, permitiendo a la sociedad conocer su territorio, preservar sus valores y ponerlo a su propio servicio. Las lecciones de Prats [197, (2004)], Halbwachs (1997, [2004]) y Stavrides (2006) sobre la memoria colectiva y el patrimonio; los estudios de Cliff Tandy (1979) dedicados a los vínculos de la industria y la minería con el paisaje; las tesis doctorales de Domenech (2006), Pérez (2007) y Garcés (2007) sobre paisajes mineros concretos; una serie de artículos de autores como Sabaté, Marchán, Aguilar y otros; además de las fuentes específicas dedicadas al caso de estudio, resultan fundamentales para cumplir con los objetivos de este trabajo.

El artículo se divide en dos partes: Primero se expone la evolución de Amiantos desde el inicio de la explotación hasta el cierre de la mina y la actualidad. La segunda parte se dedica a reconocer sus valores, materiales e inmateriales.

En cuanto a la metodología de trabajo, primero se realiza un estudio de fuentes bibliográficas generales sobre la minería y sus paisajes, además de una serie de trabajos específicos dedicados a casos concretos que no solo ofrecen un conocimiento imprescindible de este tipo de territorios, sino que permiten además construir una metodología de análisis consistente para su implementación en el caso de estudio. A continuación se analizan los recursos específicos disponibles sobre 
Amiantos (artículos, documentales, mapas y fotos antiguas y actuales) y se intenta entrecruzarlos para sacar información relacionada con su estado pasado y actual. Para cumplir con las exigencias de un análisis más profundo que permita la construcción de un inventario de recursos patrimoniales, se han realizado visitas al sitio y conversaciones con los antiguos residentes y trabajadores de la mina, que aportan información sumamente valiosa. A partir de aquí se analizan los valores de Amiantos en tablas, mapas y descripciones que verifican su importancia como legado de la minería chipriota y seña de identidad colectiva.

\section{La mina de Amiantos: pasado y presente}

\subsection{Evolución histórica: el encaje espacial y temporal}

Chipre es famosa por sus reservas mineras durante todas las etapas de su evolución histórica. Su explotación desempeña un papel significativo en el desarrollo económico, social y cultural de la isla. La explotación minera de principios del siglo XX se reparte entre cobre, calcopirita, pirita, oro, cromita y fibras de amianto. Ya entonces el amianto ${ }^{1}$ constituye un recurso relevante para la economía del país, y la mina de Amiantos en la periferia de Troodos (distrito de Lemesos), es la más grande de Europa y una de las más importantes del mundo. En ese mismo período funcionan otras minas en diferentes lugares de la isla, la mayoría de las cuales se cierran en los años ochenta, provocando repercusiones socioeconómicas y medioambientales. Después del declive de la actividad minera, las minas se abandonan y caen prácticamente en el olvido por parte de la sociedad chipriota, mientras que las nuevas generaciones ignoran su existencia y la del pasado minero del país. No obstante, con sus vestigios y sus historias muestran el significativo papel que desempeña la industria extractiva en la evolución de la isla, acentuando la necesidad de preservarlos.

La zona minera de Amiantos ocupa un área de $3,5 \mathrm{~km}^{2}$, en el Parque Forestal Nacional de Troodos, rodeada por pequeños pueblos construidos en los valles y laderas de la cordillera (Figura 2). La extracción del amianto empieza en 1904, en el contexto de una alta demanda por parte de la industria internacional. Cabe destacar que en esa época, y hasta el 1959, Chipre es colonia británica, y la población tiene que enfrentar notables dificultades en su vida cotidiana: pobreza, desempleo, pago de impuestos y escasos recursos económicos. Debido a eso, el comienzo de la explotación minera se percibe como una oportunidad de desarrollo económico, tanto de las poblaciones de la periferia como de los habitantes de toda la isla, que se trasladan a Amiantos para trabajar en la mina (Amiandos, Consulta: 16/11/2016). Hasta 1950, las operaciones se ejecutan de manera artesanal, a cielo abierto, y ocupan a muchos trabajadores. Se estima que, en los años 1920-1930, cuando la actividad minera llega a su apogeo, siendo el recurso económico más importante de Chipre, más de 10.000 hombres y mujeres trabajan allí, en condiciones muy duras e insanas (Papapetrou, 2014).

La alta demanda de amianto en los países europeos impulsa la industrialización de las operaciones. A principios de los años 20 entra en funcionamiento el funicular que conecta la mina con el puerto de Lemesos, desde donde el amianto se exporta a Europa, pero la mejora de las vías de transporte y la introducción de camiones lleva al abandono del funicular hacia 1950. Además se construyen nueve molinos de trituración para la clasificación y limpieza del mineral, que en los 60 se sustituyen por la fábrica de enriquecimiento, que incorpora técnicas más avanzadas. La mecanización progresiva de los procesos sustituye la producción artesanal, llevando a la reducción de la población minera y al abandono gradual del poblado minero (Sava A.; Christou, C., comunicación personal, 26/12/2016).

Situado en las montañas de Chipre, la transformación del paisaje de Amiantos a lo largo del siglo XX está estrechamente vinculada con la compleja topografía del lugar, caracterizada por laderas y zonas forestales a su alrededor. El área de la mina consta de tres partes: la zona de extracción

\footnotetext{
1 "El amianto es un mineral metamórfico fibroso, compuesto por fibras largas, suficientemente flexibles y resistentes a altas temperaturas. Debido a sus propiedades, se ha usado intensivamente en la industria, tanto en la construcción, como en el sector automovilístico y en la fabricación de textiles, envases, revestimientos, etcétera (Puche, 2010). El tipo que se encuentra en Chipre es el crisótilo o amianto blanco que aparece en forma de venas en las rocas serpentinas de la periferia de Troodos. A principios del siglo XXI, empieza a prohibirse el amianto en los países desarrollados a causa de sus efectos sobre la salud, y definitivamente en la Unión Europea desde 2005" (International Chrysotile Assosiation, 2015).
} 
del mineral, la de producción con las fábricas y equipamientos y la residencial. La primera está situada en la parte oeste y su explotación continua con el método a cielo abierto, lo que le ha conferido la forma de un cráter. Las fábricas con la maquinaria, los almacenes y los equipamientos de producción se ubican al Noreste del cráter de extracción y otras hacia el Sur. No se puede pasar por alto la existencia de notables cantidades de desechos y escombros apilados en las laderas de la mina, que ocupan un área considerablemente extensa (Loizides, 2013).

Hasta 1982, la empresa obtiene notables ingresos de la exportación del amianto; Se estima que de 1904 a 1988 se extraen 150 millones de toneladas de roca, de las cuales se produce un millón de toneladas de mineral (Loizides, 2013). Sin embargo, en el contexto de la campaña internacional contra el uso del amianto se empiezan a experimentar problemas financieros que llevan a su declive y al abandono de la mina y del poblado en 1988, dejando millones de escombros en el paisaje e importantes problemas medioambientales, económicos y sociales.

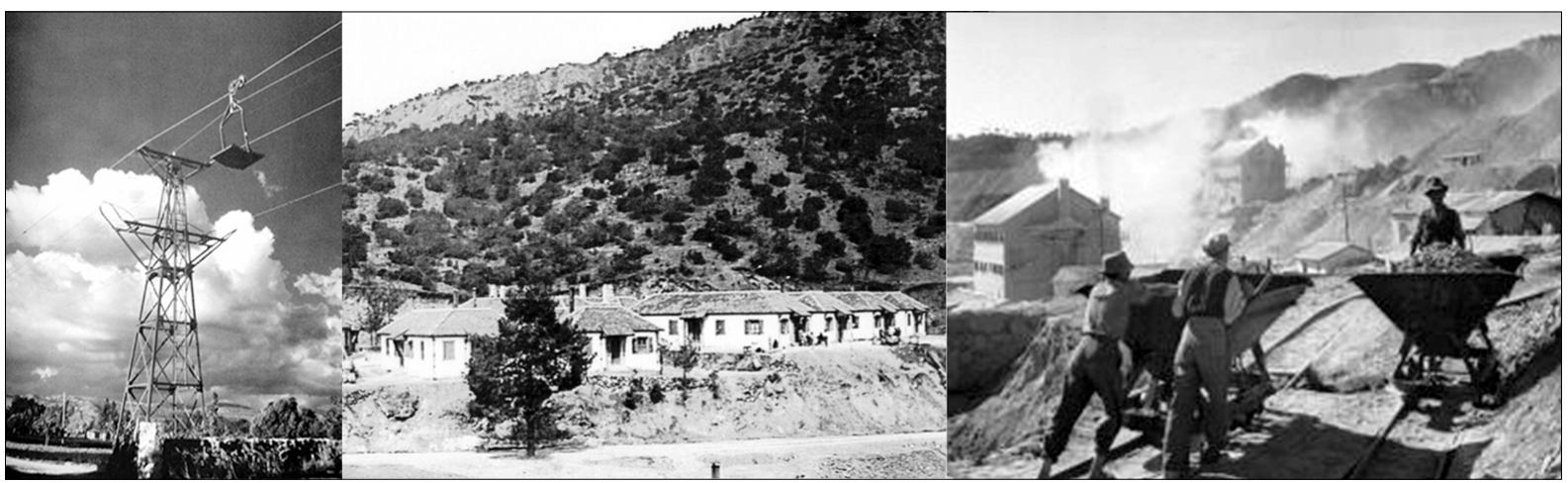

Figura 1. Fotos históricas de Amiantos antes de los años 50. Fuente: Archivo histórico del Museo Municipal Pattichion de Lemesos.

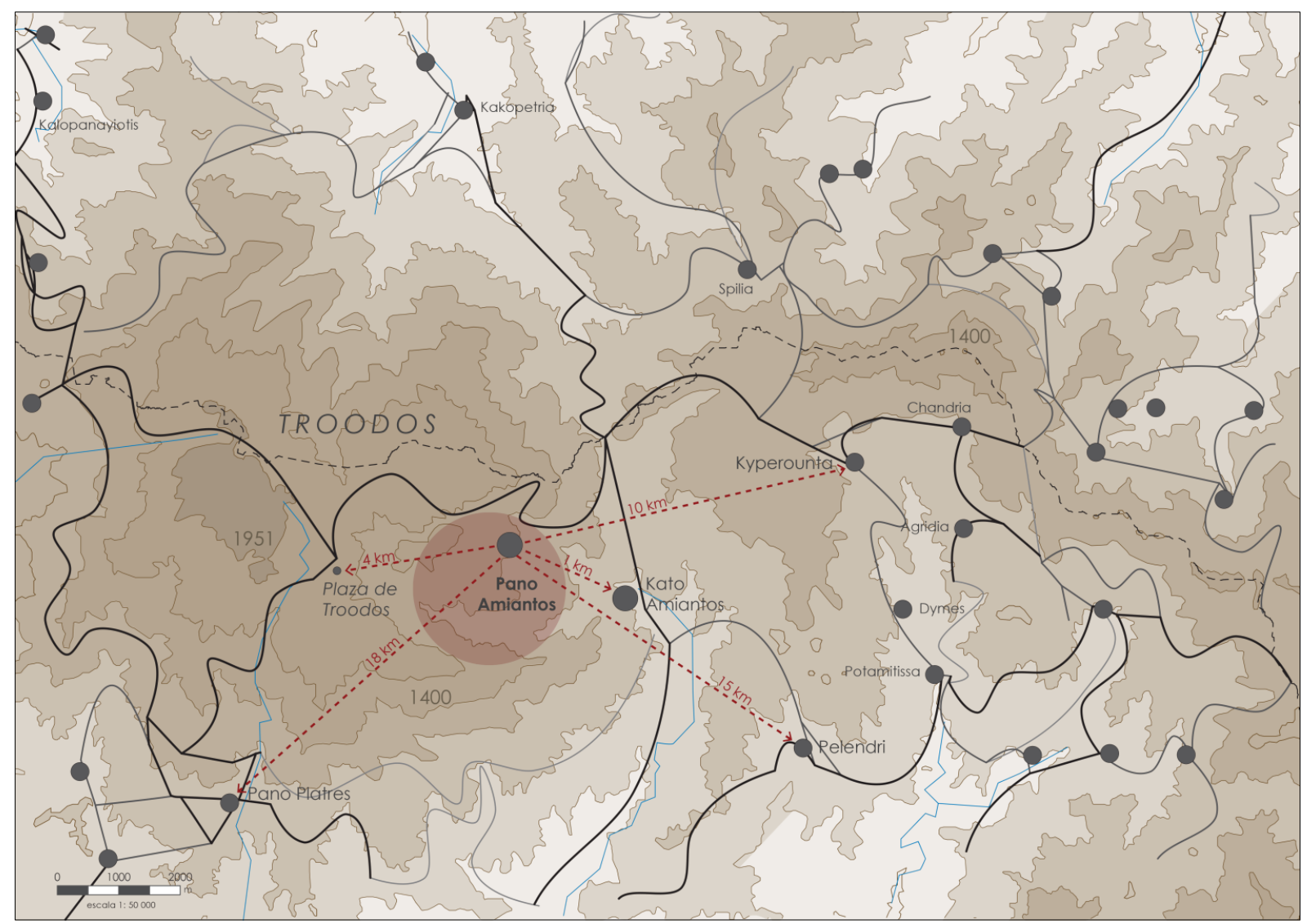

Figura 2. Relación de Amiantos con su entorno inmediato y pueblos cercanos. Fuente: Elaboración propia a partir de Google Earth. 


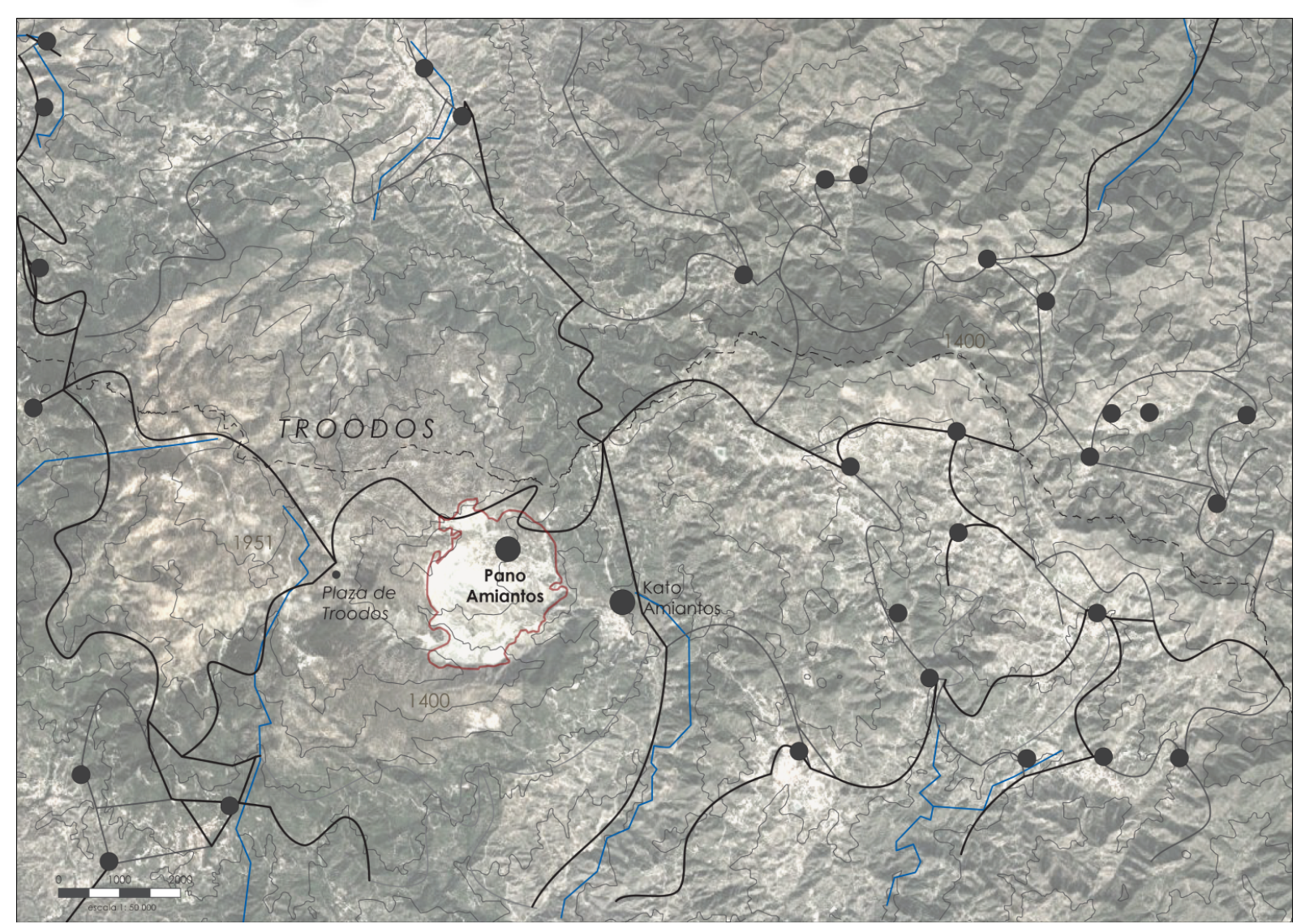

Figura 3. Topografía de Amiantos y de su entorno. Fuente: Elaboración propia a partir de Google Earth.
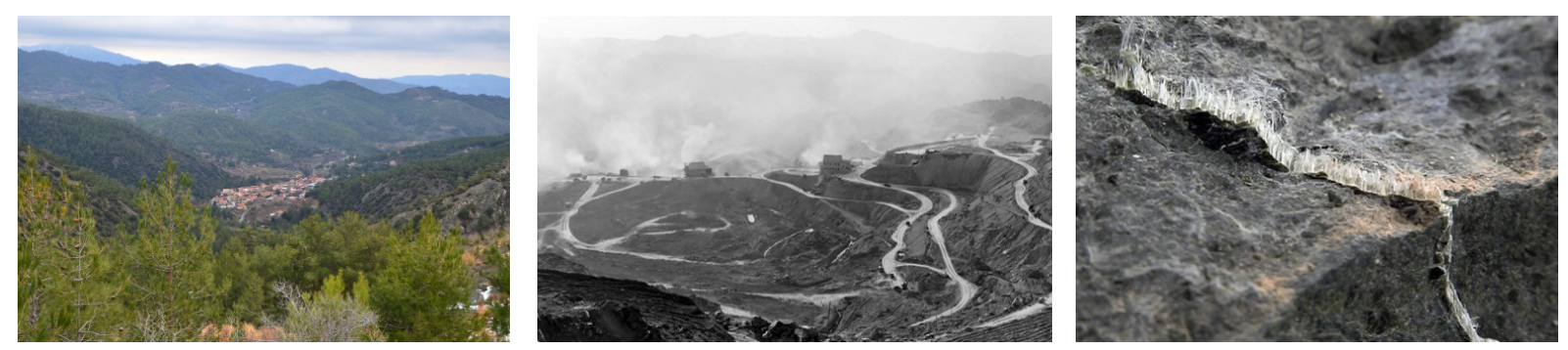

Figura 4. A la izquierda, el contexto físico de la mina. Fotografía de la autora.

Figura 5. En el centro, extracciones en los años 50. Fuente: Archivo histórico del Museo Municipal Pattichion de Lemesos. Figura 6. A la derecha, el amianto en su forma natural. Fuente: Papapetrou, 2014.

\subsection{La sociedad de Amiantos y el modelo del poblado minero}

"Las sociedades y los grupos sociales definen lugares reconocibles, donde las huellas del pasado forman la base material de la memoria colectiva" (Stavrides 2006)

Las minas suelen estar cargadas de valores históricos, sociales y culturales. Por ello, los paisajes mineros se pueden percibir como "...una síntesis del territorio basado en la vida y el trabajo que a lo largo del tiempo se han acumulado sobre el espacio" (Domenech, 2006, p.14). La mina de Amiantos, en concreto, representa un período de ochenta años de historia, en el que se evoluciona desde una sociedad auto-organizada y estrechamente vinculada a la actividad extractiva.

$\mathrm{Al}$ inicio, la mayoría de obreros viven en alojamientos temporales, en la parte norte, o van y vuelven caminando desde sus pueblos. Después de los primeros años, los albergues iniciales se transforman en casas permanentes, que llegan a formar un pueblo completo, con su propia autoridad comunitaria, complementado por servicios como escuelas, hospital, iglesias, policía, tiendas y espacios de ocio, como cafeterías, un cine y un campo de fútbol. Así se forma la comunidad de Pano Amiantos, integrada por los mineros y sus familias (Loizides, 2013; Papapetrou, 2014). De manera parecida evoluciona el pueblo de Kato Amiantos (Amiantos Bajo) en los años 20, a un kilómetro de 
distancia de la mina, para albergar a los trabajadores que vienen desde lejos. Estudiando su estructura original, se puede argumentar que Pano Amiantos tiene una presencia significativa con características urbanas, y evoluciona como una comunidad completa y autosuficiente. No obstante, su característica principal es la coexistencia del uso minero con el residencial, o mejor dicho, la evolución del mismo definida por la industria extractiva.

En cuanto a las casas, distinguimos tres tipologías diferentes que corresponden a las diferentes clases sociales en la mina: residencias grandes y de dos plantas para los directores de la empresa, casas para los trabajadores con puestos relativamente altos y barracas para los obreros (Kyriakides, comunicación personal, 28/12/2016). Además existen barrios que constituyen puntos de referencia reconocibles entre los habitantes y la gente de la periferia.

La sociedad de los mineros de Amiantos y sus familias constituye un caso típico y representativo de la transición de la actividad rural a un tipo de trabajo totalmente distinto, que produce la proletarización de una parte importante de la población chipriota, considerando que, en los años 30 , el $17 \%$ de la misma trabajaba en las minas. En este contexto, a través de las operaciones mineras emerge la estructura de una sociedad adaptada a las condiciones de trabajo de cada momento. Se trata de un grupo de personas organizado que desarrolla un sentido de "pertenencia" a un grupo social concreto, cuyos miembros tienen experiencias, valores y normas comunes. La organización del trabajo en la mina contiene elementos que caracterizan un modelo de trabajo capitalista, definido por la transición hacia un estado de proletarización, división de tareas, explotación de la clase laboral y lucha de los trabajadores contra las duras condiciones laborales (Loizides, 2013).

La falta de cualquier cautela frente a las repercusiones del amianto a lo largo de la actividad extractiva deja los obreros y a sus familias expuestos al gran peligro de este material tóxico. La ignorancia de su impacto produce el fallecimiento de muchos trabajadores y residentes de la periferia de Troodos, antes y después del cierre de la mina. Cabe señalar que en las minas de Chipre, y sobre todo en Pano Amiantos, tienen lugar huelgas y manifestaciones importantes contra las medidas duras e inhumanas impuestas por el gobierno colonial de los ingleses. Las huelgas más importantes se llevan a cabo en los años '40, cuando los mineros, apoyados por sus familias y gran parte de la población chipriota reivindican sus derechos a la salud, la jornada laboral de ocho horas, la subida de sueldos y otros beneficios, que progresivamente van alcanzando.

Como Leonel Pérez destaca en su tesis doctoral (2007, p. 218) refiriéndose a los poblados de Lota Alto y Sewell en Chile, los campamentos mineros llegan a ser paisajes singulares definidos por la compleja interacción entre naturaleza y cultura y específicamente la influencia de la acción del hombre sobre el territorio con fines productivos. Se podría argumentar que en el territorio de Amiantos se aglutinan características y singularidades parecidas a las anteriormente mencionadas que se encuentran tanto en la dependencia de las casas obreras de la actividad extractiva, como en la topografía del lugar. De la misma manera que se forman los campamentos mineros chilenos, Amiantos evoluciona adaptándose a las circunstancias topográficas y a la necesidad de integrarse en la zona para explotar sus recursos. Esta mezcla del uso industrial con la naturaleza, además de la coexistencia del mundo residencial y del trabajo, ha convertido el paisaje en una amalgama de valores diversos, que le otorgan una idiosincrasia particular. Asimismo, las similitudes observadas entre los paisajes mineros, pueden demostrar que esta actividad productiva ha generado patrones particulares derivados de los procesos de explotación y ocupación que transforman estos lugares a lo largo de los años, definiendo así una fuerte cultura en la construcción del territorio. Y como afirma Jaume

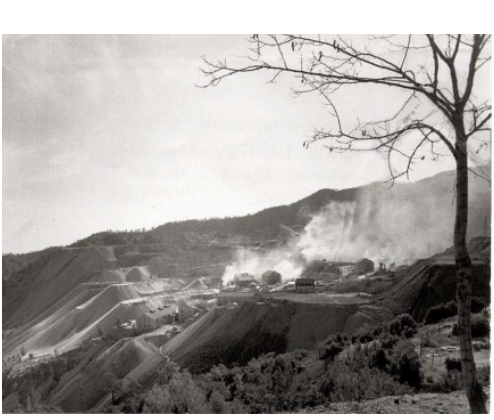
Domenech (2006, p. 15) analizando los patrones en la transformación de la cuenca minera asturiana, "[...] la formación de los asentamientos recoge la identidad del lugar y resulta la primera expresión de cultura, tradición y recursos, mucho más allá del valor de los elementos individuales". 

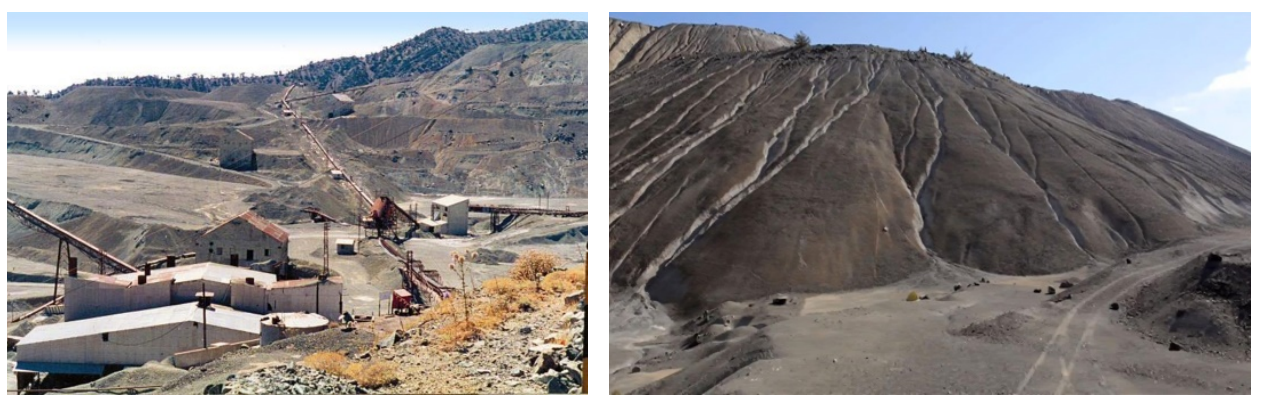

Figura 8. La mina en los años 70. Fuente: Archivo histórico del Museo Municipal Pattichion de Lemesos.

Figura 9. Escombros apilados en las laderas de la mina. Fuente: Papapetrou, 2014.

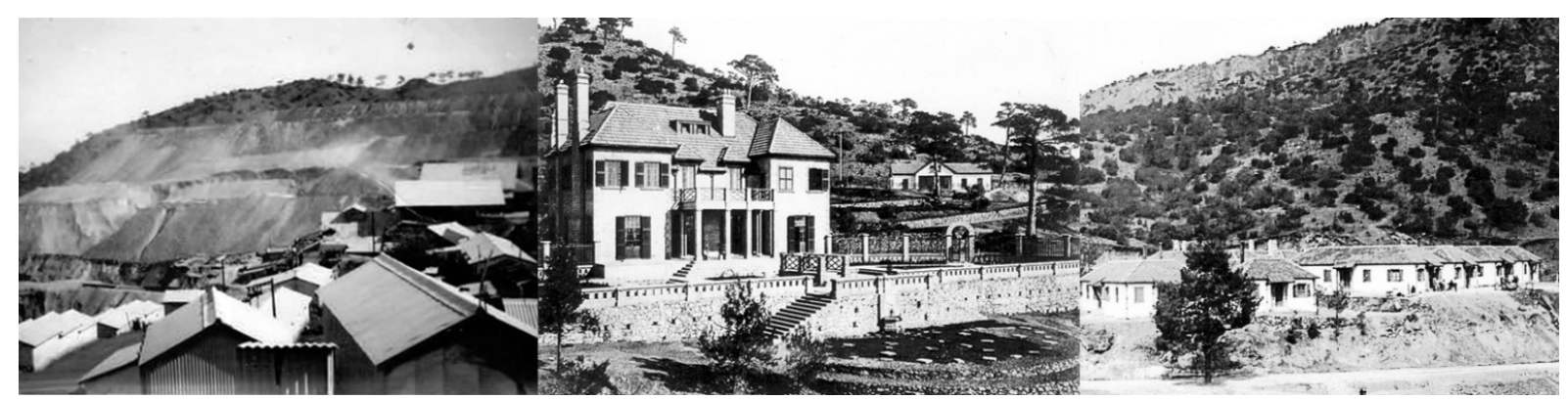

Figura 10. Barracas obreras.

Figura 11. La casa de un director.

Figura 12. Casas para los trabajadores. Fuente: Archivo histórico del Museo Municipal Pattichion de Lemesos.

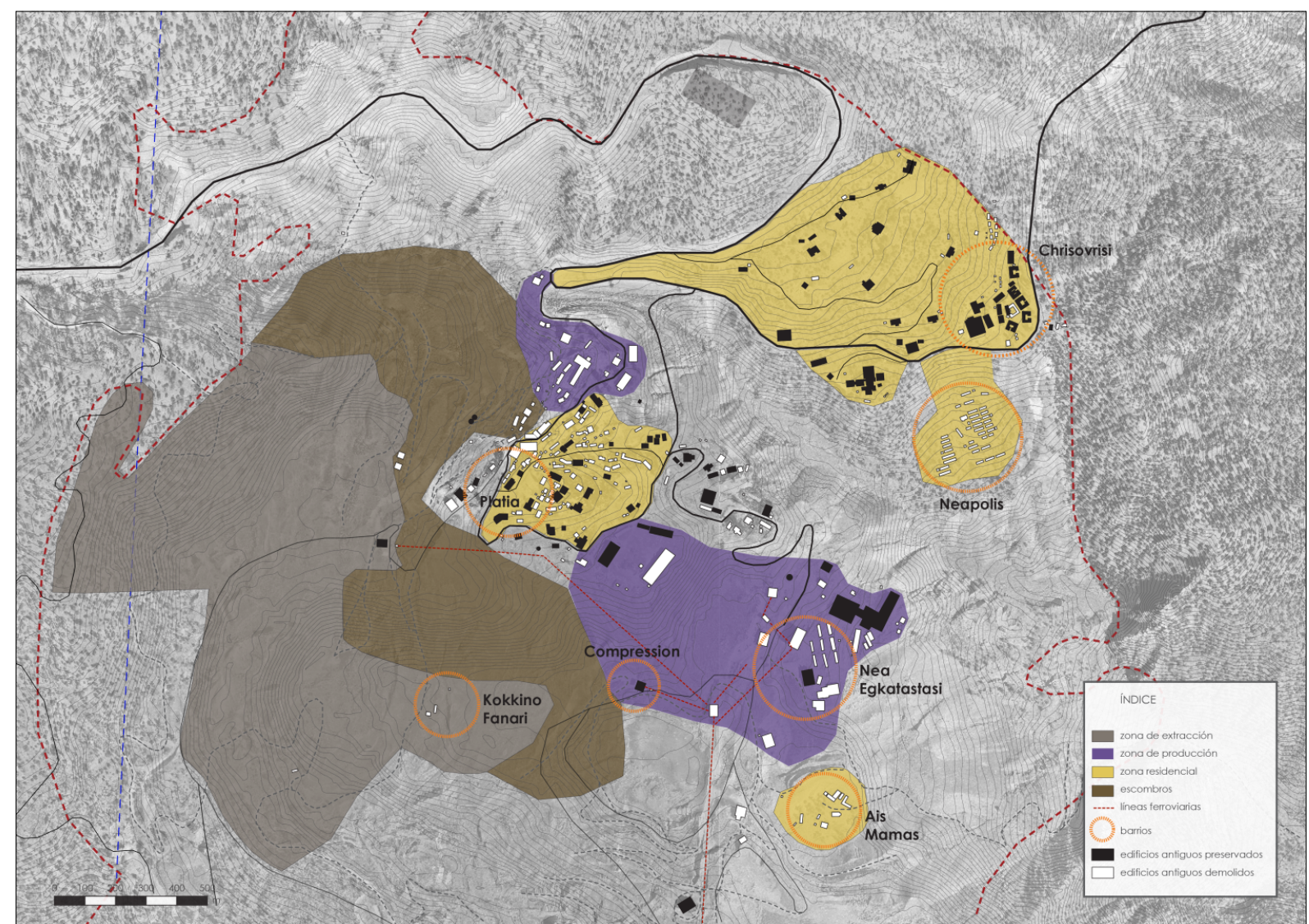

Figura 13. Zonas según usos y barrios de la mina en su estado original, foto aérea 1963. Fuente: Elaboración propia a partir de datos del Catastro de la República de Chipre.

\subsection{Estado actual}

Hoy en día, Amiantos se encuentra en un estado bastante alterado, a causa de la demolición de varios edificios, la desaparición de la maquinaria, su abandono y degradación durante las tres 
últimas décadas. Después de su cierre, adquiere el aspecto de un paisaje lunar, como resultado de las extracciones intensivas, sin ninguna presencia de vida. La necesidad de recuperar el paisaje dañado y darle un estado más "natural" lleva a la redacción del Plan de Restauración medioambiental, que se pone en marcha en 1995 y sigue evolucionando hasta hoy. Las obras se centran en primer lugar, en la estabilización de los escombros depositados en las laderas de la mina, para minimizar el riesgo de deslizamiento. Posteriormente se afronta la reforestación y revegetación del terreno (Tsintides, 2013). A pesar de las condiciones adversas que complican las obras, la restauración de la mina muestra actualmente un progreso impresionante, y se estima que, con la finalización del proyecto, no antes del 2035, las condiciones medio-ambientales de Amiantos van a mejorar notablemente (Kyrou, 2010). Sin embargo, la recuperación se limita al medio ambiente y el paisaje, y prácticamente nadie ha mostrado ningún interés por preservar los recursos patrimoniales. Por consiguiente, las casas y las fábricas se vacían, los barrios y los espacios públicos resultan poco reconocibles, la red de vías muy alterada y los recuerdos de la gente de Amiantos se apagan sin reconocimiento de su valor como testimonios de su propio pasado.

En cuanto a usos se pueden distinguir una zona industrial, que alberga las fábricas que aún quedan en pie y algunos edificios auxiliares; una residencial con las casas de los directores y de los obreros, otra de usos mixtos que incluye las casas de los trabajadores, así como oficinas y almacenes, temporalmente ocupadas por el Departamento Forestal; la antigua escuela primaria, que se ha rehabilitado como Centro de visitantes del Geoparque de Troodos; algunos edificios industriales abandonados y la iglesia de Apostolos Varnavas. Hacia el Norte se extiende la zona forestal. El 45-50\% de la mina está ocupado por la zona recuperada y reforestada, que ha sustituido una parte importante de las antiguas escombreras. Ésta se complementa con un jardín botánico, en funcionamiento desde el 2010, a cargo del Departamento Forestal y el cráter de extracción que está siendo transformado en un lago artificial.

El paisaje de Amiantos y su evolución muestra un valor patrimonial con varias dimensiones. A partir del reconocimiento de sus valores se puede construir el relato que cuente su historia, convirtiéndolo en un espacio comunicativo que atesore y transmita información de un pasado relevante (Sabaté, 2000-2004).

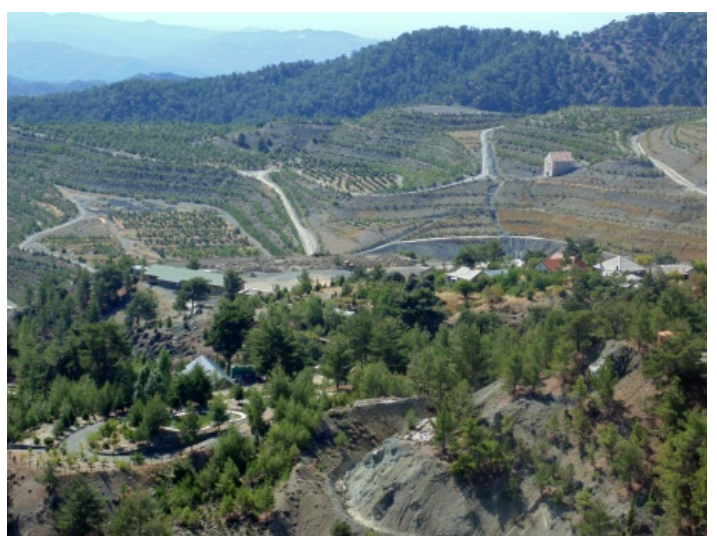

Figura 14. La mina en su estado actual.

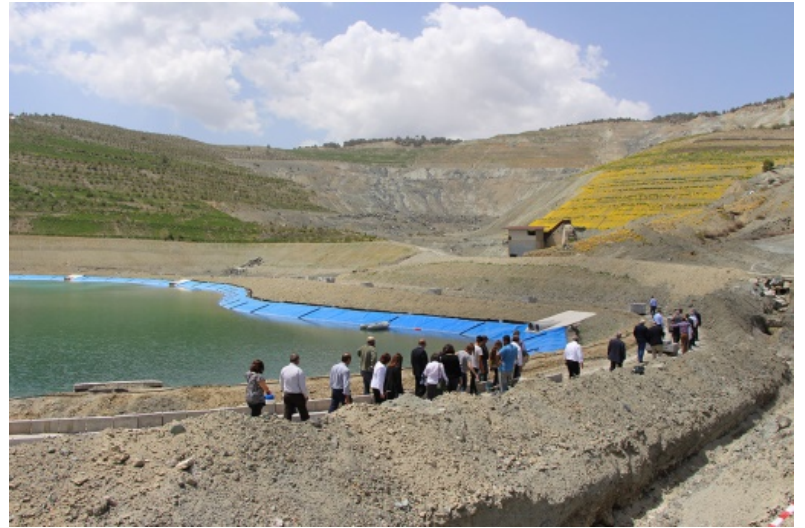

Figura 15. El cráter reconvertido en lago.

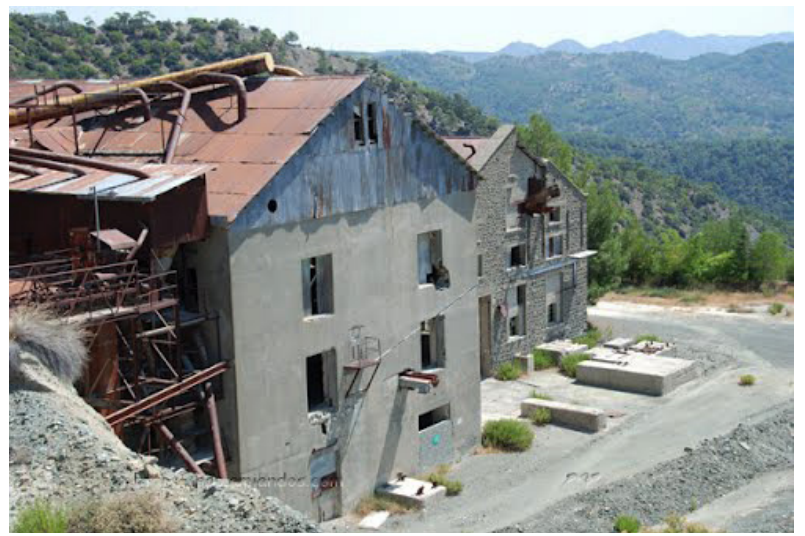

Figura 16. El Fiber Mill, 2016. Fuente: Fotografías de la autora. 


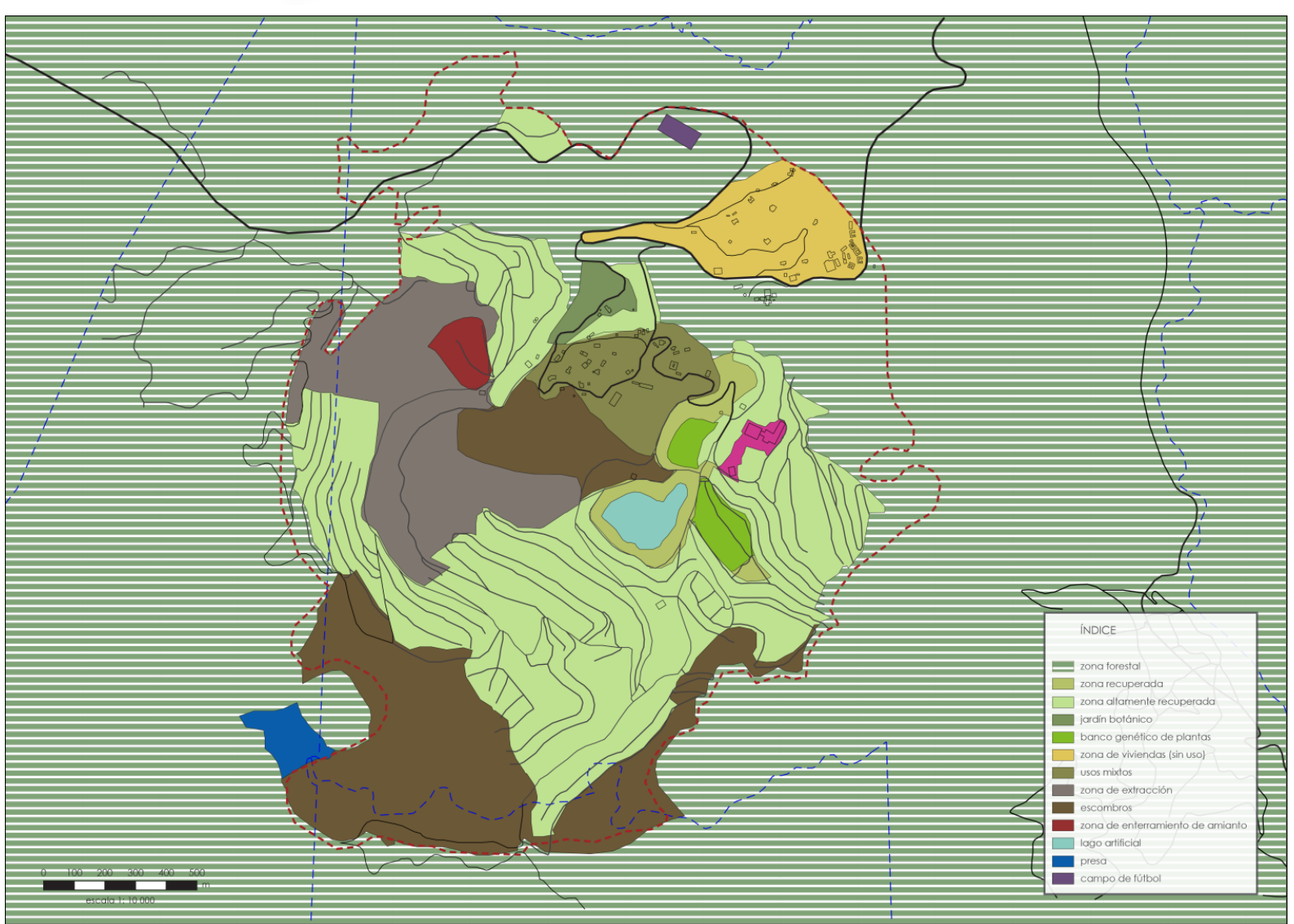

Figura 17. Zonas de usos de la mina en su estado actual. Fuente: Elaboración propia a partir de datos de Loizides, 2013.

\section{Los valores como desafíos: inventario de recursos tangibles e intangibles}

Para apreciar un paisaje cultural primero hay que entenderlo, mediante estudios y observaciones que permitan reconocer sus valores. En los paisajes mineros, en particular, solemos encontrar un conjunto heterogéneo de elementos tangibles e intangibles, muebles e inmuebles, archivos documentales $\mathrm{y}$ vestigios inmateriales. Entre todos destacan elementos como las fábricas, instalaciones de grandes dimensiones, infraestructuras o maquinaria, que no solo constituyen testimonios históricos de las actividades extractivas, sino también elementos dotados de cierta belleza y calidad arquitectónica. La cantidad y la tipología de estos vestigios varían según la duración y las dimensiones de la explotación, el método extractivo y otros factores que dotan a cada lugar de una identidad singular. Según el tipo de minería, las áreas de extracción incluyen diferentes estructuras, maquinaria, infraestructuras de transporte, sistemas de suministro de energía, servicios de producción, administración e infraestructura social, además de diferentes formas de laboreo y organización técnica de las cuencas mineras, elementos patrimoniales que caracterizan la identidad del lugar (Pérez y Sánchez, 2010). Al tratarse de territorios de gran complejidad, su regeneración exige unas claves metodológicas, que partan de la identificación de los recursos disponibles, de su evaluación y jerarquización y posteriormente su interpretación según la estructura narrativa más adecuada (Sabaté, 2000-2004).

Con respecto a Amiantos, se pretende construir el inventario de los bienes mineros, como base de partida para su regeneración y la salvaguarda de su identidad. Entre éstos distinguimos "lo tangible", entendido como los vestigios físicos, y "lo intangible", que se refiere a los vestigios inmateriales. Los primeros se refieren a los edificios, la infraestructura, la maquinaria y otros elementos relacionados con el poblado, la actividad minera y la vida cotidiana en Amiantos, que aún se mantienen. De los elementos visibles no se pueden excluir los recursos medioambientales, puesto que la evolución del lugar a lo largo de los años ha estado ligada a su geología singular, topografía y zona forestal que lo rodea, que, al mismo tiempo, se han visto gravemente afectados por la explotación minera. Esta identificación se considera crucial, ya que los elementos preservados en el territorio constituyen recursos para la identidad y los vínculos más inmediatos con el pasado, que deberían desempeñar un papel predominante en su futura transformación. 


\subsection{Vestigios materiales: lo tangible}

"La permanencia de una edificación significa para los interesados la permanencia de sus recuerdos" (Halbwachs, 1950, p. 167).

En el ámbito minero se conservan una serie de edificios residenciales, industriales, espacios auxiliares y de servicio. Las viviendas son de tres tipologías diferentes, que se ajustan al perfil de sus usuarios: casas grandes de dos plantas para los directores de la empresa, casas de los trabajadores y conjuntos residenciales con servicios comunes para los obreros. Las casas de los directores destacan por elementos típicos de la arquitectura de la época, construcción de ladrillo, altos techos de madera y diseño de sus jardines, demostrando el nivel de sus propietarios. Las casas de los trabajadores, por el contrario, son de tamaño reducido, construidas con piedra local. Más allá de éstas se disponen edificios de servicio: el hospital, un conjunto de espacios de proporciones neoclásicas conectados mediante galerías de vidrio, la panadería, la tienda cooperativa, la iglesia con su campanil metálico, el club, el restaurante de los trabajadores y la escuela primaria. La escuela se aloja en un edificio de alto interés arquitectónico, que actualmente se ha convertido en Centro de visitantes del Geoparque de Troodos: un edificio de ladrillo con techo a cuatro aguas, del cual sobresalen seis chimeneas, y un pequeño patio interior. En cuanto a los edificios industriales, se encuentran dispersos al Sur y al Noreste del cráter de extracción e incluyen el edificio principal de producción de amianto, conocido como Fiber Mill, tres antiguos molinos, dos trituradoras y la subestación de la empresa eléctrica. El Fiber Mill, construido en 1920, es el conjunto industrial más grande de la mina, de tres plantas, donde se ha mantenido la única muestra de maquinaria: máquinas para la trituración del mineral, tubos, engranajes, corredores, y escaleras, todos oxidados y deteriorados por el desuso. El uso industrial se complementa con edificios de servicio, como las oficinas de la empresa, el taller de mantenimiento de la maquinaria y edificios auxiliares, como almacenes y garajes. Entre los vestigios físicos destacan barrios, caminos y espacios públicos, que conjuntamente formaban elementos estructurales del poblado, aunque, en su mayoría, están deteriorados y resultan poco reconocibles.

No se puede pasar por alto el valor ambiental y paisajístico de Amiantos como parte de sus recursos tangibles. La mina y su entorno, con una rica variedad de ecosistemas y biotopos, forman parte del Parque Forestal Nacional de Troodos y al mismo tiempo están protegidos por la red "Natura 2000". La topografía, la geología, las condiciones climáticas y el sistema hidrológico de la cordillera de Troodos han permitido el desarrollo de especies de la flora más diversa de la isla y es uno de los hábitat más importantes en el ámbito mediterráneo. Además de esto, las formaciones geológicas de Troodos aportan información imprescindible relacionada con el movimiento de las placas tectónicas y la génesis de la Tierra, convirtiéndole en un modelo geológico singular que atrae científicos e investigadores de todo el mundo (Vasiliou, 2016).

Esta confluencia de factores culturales y naturales en el ámbito de Amiantos, exige su reconocimiento como patrimonio en su sentido más amplio: natural y construido (Sabaté, 2001), ambos conjugados en una visión integral del paisaje minero.

El paisaje de Amiantos se encuentra en una situación bastante alterada con respecto a la original, debido a que una parte importante de las edificaciones se han demolido, la mayor parte de la maquinaria se ha vendido y el sistema de vías se ha alterado con el paso del tiempo. La foto aérea del 1963 constituye un testimonio importante para apreciar esta transformación. Comparando el estado previo con el actual, se entiende que la consistencia original de los barrios se ha perdido, lo que se intensifica por la ausencia de los edificios demolidos que constituían puntos de referencia en la vida cotidiana de los antiguos trabajadores y sus familias. Al mismo tiempo, las intervenciones están centradas en la recuperación del paisaje, dejando el patrimonio minero e industrial desatendido y expuesto al deterioro con el paso de los años. En ningún caso se pretende infravalorar la necesidad de cerrar las heridas provocadas al entorno natural por la extracción intensiva, sino hacer hincapié en la necesidad de proteger la identidad de Amiantos y sus antiguos usuarios y reintegrarla en la vida cotidiana de los mismos, como una nueva oportunidad de desarrollo.

Aunque se han dado pautas relacionadas con la protección del patrimonio industrial del conjunto a través de un plan orientativo para su futuro aprovechamiento (Loizides, 2013), todavía no se 
ha programado ningún proyecto que apunte a estos objetivos. En cuanto a los edificios, aunque muchos de ellos presentan valores históricos y arquitectónicos, todavía no se han catalogado ni tampoco se ha reclamado su protección. Esto significa una falta de reconocimiento del valor del paisaje minero como patrimonio, a causa de las repercusiones derivadas de su actividad, o debido a la falta de proyectos parecidos en el ámbito chipriota, que aunque se encuentran con frecuencia en el resto de Europa, siguen siendo desconocidos en la isla.

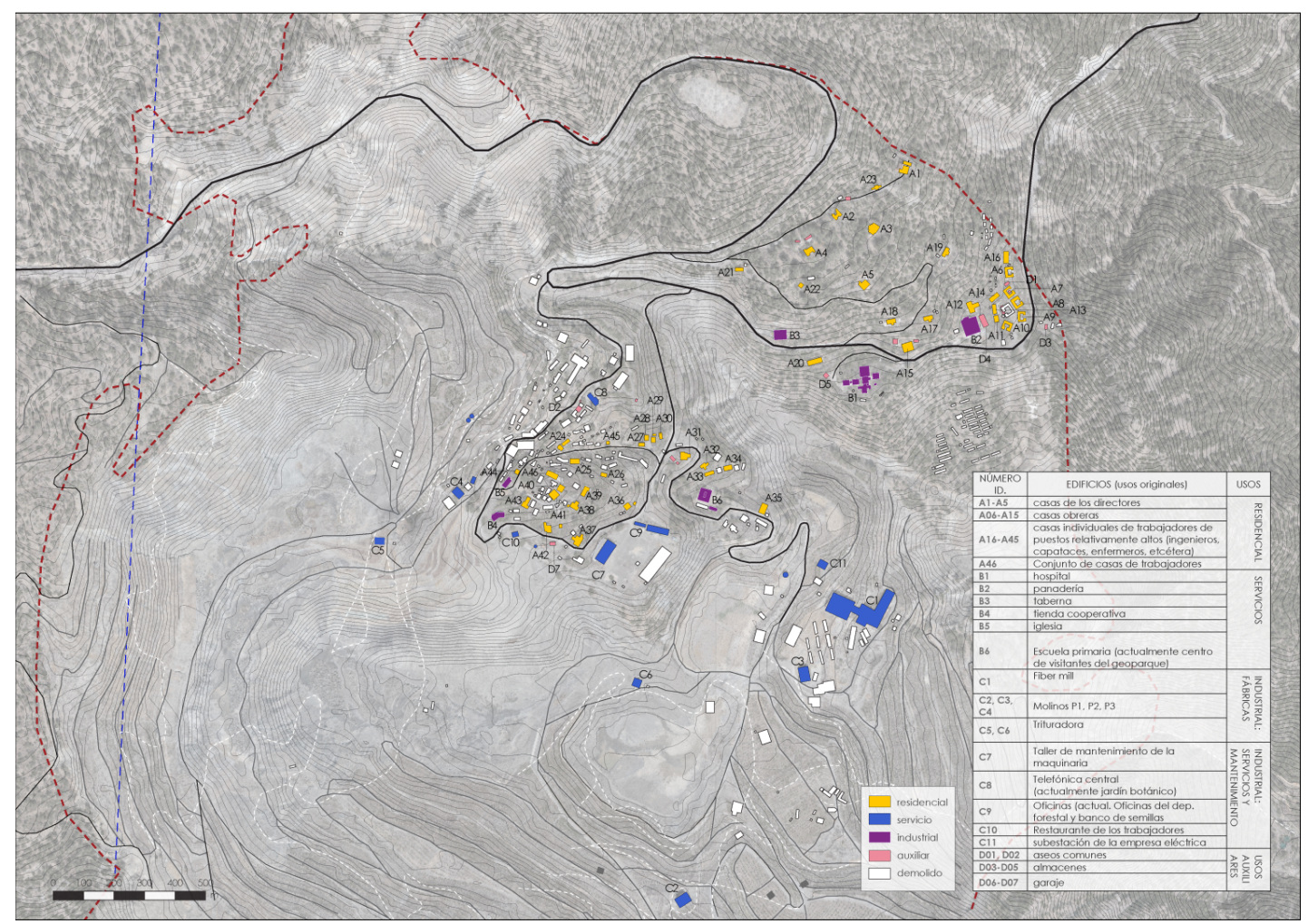

Figura 18. Edificios preservados: Foto aérea y tabla. Fuente: Elaboración propia a partir de datos del Catastro de la República de Chipre.

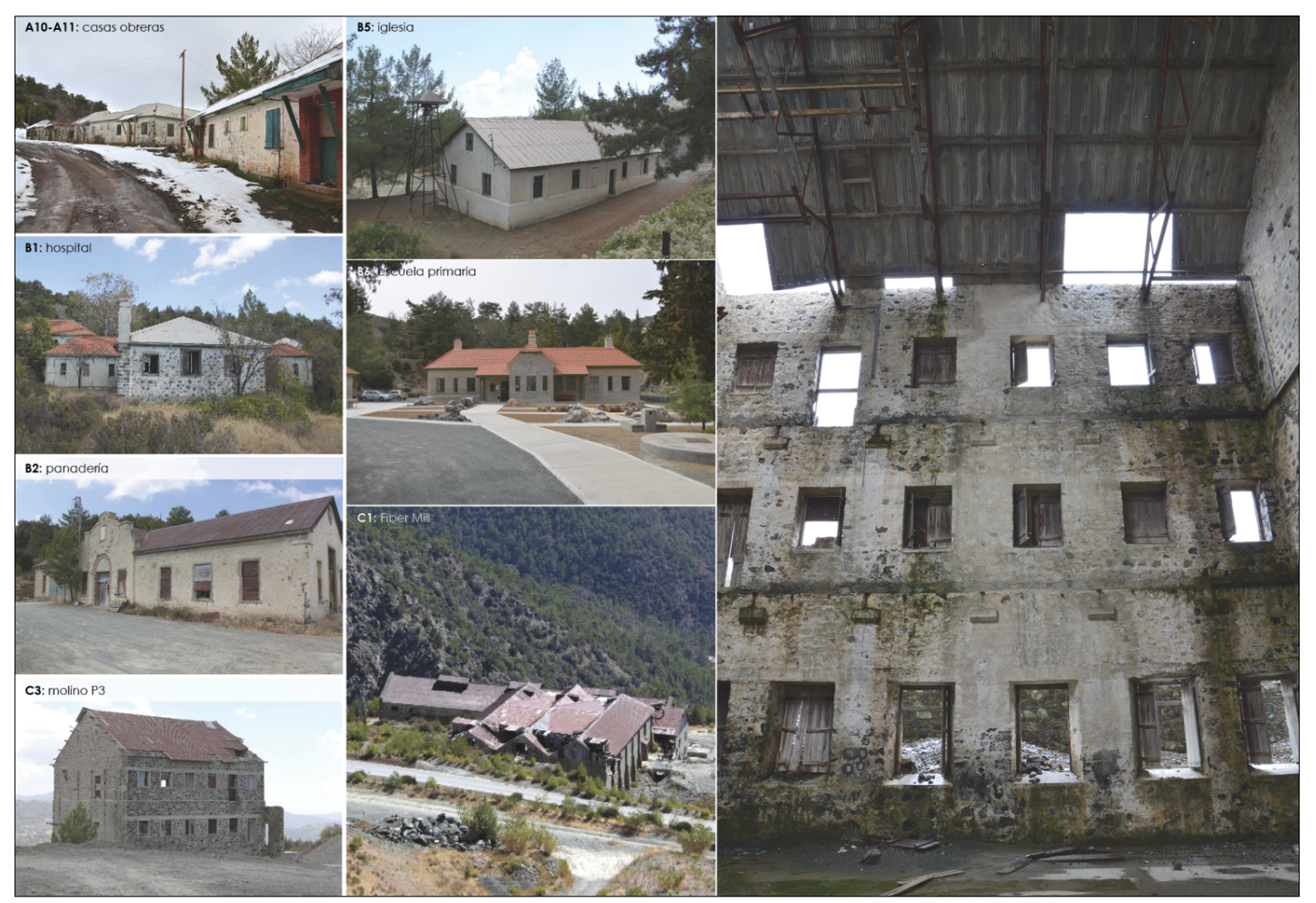

Figura 19. Edificios preservados. Fuente: Archivo de la autora. 


\subsection{Vestigios inmateriales: lo intangible}

Además de los vestigios materiales, los paisajes mineros gozan de un patrimonio inmaterial significativo que forma parte indispensable de la memoria de dichos lugares. Éste consiste en elementos sociales, económicos y culturales superpuestos que han evolucionado a lo largo de las explotaciones. Incluye las técnicas e innovaciones adoptadas por los diversos oficios, las memorias vivas de la vida cotidiana y la actividad laboral que llegaron a formar una cultura minera definida por la simbiosis de las actividades productivas y el uso residencial en los poblados, los comportamientos sociales, los acontecimientos y las tradiciones de grupos de diversa procedencia. En varias ocasiones, esta cultura perdura tras el abandono de las explotaciones y se transmite a través de los recuerdos de los antiguos residentes y trabajadores, que son los protagonistas de este proceso. La cultura minera se reivindica por las comunidades locales como parte fundamental de su pasado y los vínculos que las unen al lugar, formando parte inherente de su memoria colectiva (Marchán y Sánchez, 2013).

La memoria es un hecho y un proceso colectivo (Halbwachs, 1950, [2004]). La narración del pasado de parte de los miembros de un grupo mediante un lenguaje y significación común supone la existencia de un sentido compartido que se establece como una entidad. M. Halbwachs (1950, [2004]) define la memoria colectiva como el proceso social de reconstrucción del pasado vivido y experimentado por un grupo, comunidad o sociedad, que se diferencia de la memoria histórica en el sentido que la última se refiere más bien a fechas y eventos registrados, independientemente de si éstos han sido sentidos y experimentados por las personas. Al contrario, la memoria colectiva pretende dar continuidad al pasado mediante los recuerdos y las experiencias del grupo correspondiente, preservando así la identidad del mismo. La reconstrucción de los recuerdos de la gente a través de sus conversaciones, contactos, rememoraciones, efemérides, usos y costumbres, además de la conservación de sus objetos y permanencia en los lugares donde han evolucionado, resulta sumamente importante en medio de un mundo en constante movimiento y transformación como el nuestro. En este contexto, la memoria acaba siendo la única garantía de que el grupo, su identidad y sus proyectos siguen siendo los mismos (Aguilar, 1991 [2002]).

En el caso de Amiantos, las memorias de su pasado, relativamente reciente, se reviven gracias a los recuerdos y narraciones de la gente que antes daba vida al lugar y actualmente vive tanto en la periferia de Troodos, como en toda la isla. En los últimos años, estos testimonios orales han atraído el interés de agentes individuales que han intentado documentarlos, como el director Paschalis Papapetrou con sus documentales "Amiantos: Pasado, presente y futuro" (2014) y "Memorias de mineros" (2007); el antiguo trabajador y miembro del gremio de los mineros Pantelis Varnava con su libro "Un minero recuerda" (1989) y varios periodistas que a menudo dedican artículos a la mina. Para aportar una documentación más a fondo de los vestigios inmateriales, he entrevistado a personas que vivieron y trabajaron en Amiantos, en busca de fuentes de primera mano, así como para entender cómo ellos mismos interpretan el paisaje minero ${ }^{2}$. Entre los recuerdos de la gente destacan las referencias a los hitos perdidos, edificios, infraestructuras y espacios públicos, que ya no existen, pero que en su momento constituían puntos de referencia fundamentales para la comunidad. Por esta razón, estos hitos se incluyen en los vestigios inmateriales que, junto con las memorias de la gente, constituyen lo que hoy corresponde a lo intangible. Cabe destacar que los recursos inmateriales no se desvinculan del espacio físico. Todo lo contrario, tienen referentes espaciales, la preservación y documentación de los cuales resulta imprescindible para la reconstrucción e interpretación de la memoria.

Ahora bien, ¿cuáles son entonces los elementos sustantivos de la memoria colectiva de Amiantos? Entrecruzando los recuerdos de la gente con información complementaria de las fuentes disponibles, se pretende entretejer un relato que cuente la historia de Amiantos. Los recuerdos se agrupan en categorías temáticas: los que se refieren a la vida laboral y a las técnicas de explotación, las memorias de la vida cotidiana y la fisonomía de la sociedad del poblado, además de los acontecimientos que se han mantenido en la memoria de la gente. Indudablemente, las memorias individuales

\footnotetext{
2 He entrevistado a seis antiguos residentes y trabajadores que actualmente viven en el pueblo de Kato Amiantos y otros de la periferia y a tres funcionarios del Departamento Forestal que actualmente trabajan en el Jardín Botánico y el Centro de Visitantes del Geoparque (diciembre 2016).
} 
siempre implican un cierto grado de subjetividad, como se puede observar en los testimonios agrupados que, aunque coinciden en cuanto al tiempo y el espacio, a veces se diferencian entre sí según las experiencias de cada persona. Debido a eso, la documentación de la memoria colectiva requiere un trabajo exhaustivo y pormenorizado acercando a los participantes y recogiendo el máximo material disponible, que debe evaluarse y comprobarse para extraer datos más precisos.

A continuación se expone una pequeña muestra de estos fragmentos seleccionados, que a veces transmiten sentimientos contradictorios: orgullo y nostalgia de un pasado que ya no existe, pero al mismo tiempo rechazo de unas condiciones laborales adversas.

"Para llenar un vagón, cada obrero debería sacar entre 85 y 90 cubos de tierra...El trabajo era muy duro [...] Cada uno de los trabajadores sacaba entre 20 y 25 vagones por día, del amanecer al anochecer [...] no habían jornadas laborales fijas ni nada" (Papapetrou, 2014).

"Todavía tengo en la memoria la imagen de los obreros colgados sobre las laderas de las montañas excavando las rocas. En las partes donde el acceso era difícil ponían dinamitas para romper las rocas y luego recogerlas" (Charidemou, comunicación personal, 30 dec. 2016).

No hay duda que en aquel momento había una explotación evidente de los trabajadores, quienes cobraban un sueldo muy bajo. El señor Economou cuenta lo siguiente:

"Trabajé en la mina durante 30 años, hasta su cierre. Mucha gente de los pueblos cercanos falleció por cáncer de pulmón [...] Eran años difíciles y había mucha pobreza, cobrábamos un sueldo mínimo con mucho esfuerzo y riesgos [...] Era un infierno, donde trabajábamos del amanecer hasta la puesta del sol. Nadie nos informó de los peligros a los cuales nos exponíamos respirando el amianto [...]" (Amiandos, consulta: 14 nov. 2016).

Pero en aquellos momentos los puestos de trabajo son tan escasos que, para los chipriotas, el empleo en las minas supone la única oportunidad de ganar el mínimo necesario para sostener a sus familias. Con la industrialización de las operaciones en los años 50 y 60, se adoptan nuevas técnicas de extracción y producción, resultando en la reducción de trabajadores y residentes de Amiantos, debido a que la mano de obra se sustituye por las máquinas. Al mismo tiempo, se introducen mejoras en las condiciones de trabajo como resultado de las reivindicaciones de los sindicatos mineros y la automatización de las anteriores labores artesanales. Por consiguiente, los recuerdos de muchos trabajadores transmiten experiencias a lo mejor menos dolorosas y un cierto grado de nostalgia por los años en Amiantos, puesto que ignoraban las repercusiones en la salud provocadas por el material extraído.

“A veces bajaba a la mina para llevar comida a mi padre. Por el polvo que había me volvía blanco, pero nadie sabía qué nos provocaba el amianto. Hoy puedo decir que sí, las condiciones de vida eran inhumanas, pero no sabíamos que estábamos expuestos en tal peligro. [...] A mí me hacía mucha impresión todo este polvo que salía de las fábricas pero no sabía lo perjudicial que era. Mi madre se murió por cáncer, tal como otros residentes del pueblo. Aunque no se ha demostrado, sospecho que la causa fue el amianto" (Christou, comunicación personal, 26 dec. 2016).

"Mi padre estaba satisfecho de su trabajo, tenía un sueldo suficiente para sostener su familia, ya que tenía un puesto relativamente alto, digamos. Y además tenían su familia cerca, sus hijos crecían en un entorno diferente, con servicios y facilidades que en otros pueblos no había" (Christou, comunicación personal, 26 dec. 2016).

Andreas Sava trabaja por primera vez en la mina en 1938, a sus 16 años, hasta que se establece la ley que sólo permitía trabajar en las fábricas después de cumplir los 18 años de edad. Debido a eso, Andreas se marcha por un tiempo y vuelve a Amiantos en los años 50, instalándose con su familia y trabajando como capataz que tiene bajo su supervisión uno de los nueve molinos. Con el abandono de los molinos se encarga de otras tareas en el taller de mantenimiento o "el workshop". Narrando sus recuerdos a la edad de 95 años, los datos a veces se mezclan, se confunden o quedan 
incompletos. Sin embargo, es impresionante que se acuerde de tantos nombres, fechas, terminología técnica, cómo las máquinas se conectan entre sí y una serie de detalles que quedan guardadas en su memoria durante más de cincuenta años.

"A la vuelta de las fiestas, el jefe nos dijo: no vayáis a los molinos; venid al 'workshop' y os repartiré otras tareas".

Debido a que la mina es la única en Chipre en la que se explota el amianto, las memorias de la gente están cargadas de un conocimiento técnico imprescindible sobre la infraestructura, los equipamientos y los métodos utilizados en este sector. Como se puede observar en sus narraciones, los antiguos trabajadores conocen mejor que nadie cómo funciona la mina, dónde está cada instalación, cómo se llama cada máquina y cada herramienta. Durante las entrevistas, a veces parece que utilizan un lenguaje diferente, una terminología especial para explicar de la manera más precisa las operaciones. Por lo tanto, los fragmentos de estos testimonios de la sabiduría popular minera, exigen su salvaguardia como parte del pasado industrial chipriota.

Preguntando a la gente sobre la estructura del poblado minero, responden que en aquellos años es equivalente a una ciudad completa, con todo tipo de servicios. La prosperidad económica que la explotación minera lleva a la zona es notable y lo confirman con orgullo todos los entrevistados. Estos testimonios son sumamente útiles para conocer el aspecto original del poblado, que actualmente está bastante alterado. Además, entrecruzando las descripciones que se refieren a los hitos del poblado, se puede localizar los mismos con relativa precisión.

Según Kyriakides (comunicación personal, 28/12/16):

"En un momento la población de Pano Amiantos alcanzó los 10.000 residentes y era algo así como Lemesos en nuestros días. A lo mejor en aquellos años no encontraras en Lemesos lo que había en Amiantos. Había cafeterías, cinema, zapateros, orfebres y mucho más. En el hospital de la mina hacían operaciones y disponía de cuarenta camas, con equipamiento propio que ningún otro hospital de Chipre tenía. Todo era perfecto."

"Era una pequeña ciudad [...] nada tenía que ver con los pueblos de aquellos años. Con su hospital, su cinema, muchas cafeterías llenas de gente, muchas tiendas y artesanos [...] se diferenciaba de los pueblos rurales" (Christou, comunicación personal, 26 dec. 2016).

Y al mismo tiempo, se ofrece información detallada que nos permite reconstruir mentalmente una imagen del pueblo más exacta, enriquecida por historias de la vida cotidiana, de manera que nos hace imaginar Amiantos vivo y activo, como era en su momento.

"La plaza estaba cerca de la iglesia, y alrededor de la iglesia había tiendas: supermercados, modistas, la tienda cooperativa, y alrededor de la plaza había casas; no era muy grande y además allí se cruzaban calles: una que iba hacia abajo, por la dirección de la tienda cooperativa, otra que iba por el otro lado y una tercera que llegaba al otro barrio. Era algo así como el centro del pueblo" (Sava, comunicación personal, 26 dec. 2016).

Charalambos Christou nace en 1944 y se traslada a Amiantos a la edad de ocho años, porque su padre trabaja allí a partir de los años 40 como capataz de un molino. Sus narraciones transmiten una cierta sensibilidad y una relación íntima con el lugar donde creció, que fortalecen sus vínculos al pasado.

\footnotetext{
"De pequeños sólo jugábamos, estudiábamos poco. Cada barrio tenía su equipo de fútbol, y organizábamos torneos. Dábamos paseos alrededor de las montañas para recoger fruta del bosque [...] vivíamos una vida hermosa, en la naturaleza, cerca de los ríos [...] como si fuera parte de una película. Yo que había vivido en Potami también, siempre hacía la comparación entre los dos lugares; los años de juventud en Amiantos eran incomparables con cualquier otro sitio. [...] A veces jugábamos con el amianto, excavábamos las rocas y tirábamos las fibras con las manos, nos gustaba que fuera así como el algodón. Era imposible pensar que este material era nocivo".
} 
En cuanto a los hitos perdidos, se definen como intangibles porque, aunque tienen una presencia física en el paisaje, actualmente no existen vestigios de ellos. Se trata de los edificios que se derriban durante las explotaciones o después del cierre de la mina, infraestructuras y equipamientos que se desmontan y espacios públicos que ya no son reconocibles en el sitio. Sin embargo, estos hitos forman parte inseparable de la memoria, debido a que siempre han sido punto de referencia para la comunidad. Su importancia se justifica por las narraciones orales, puesto que la gente siempre se refiere a ellos para contar la historia de su lugar. En palabras de Halbwachs (1950, [2004], p. 167), "[...] con cada edificio que se derrumba, un trocito de pensamiento colectivo se rompe, queda inconcluso". Sin embargo, aun sí una construcción se destruye, siempre podrá decirse que "aquí estuvo", puesto que el emplazamiento es lo último que se borra. En este caso, la importancia del espacio se vuelve doble para la memoria depositada en el mismo, puesto que "sólo el espacio es tan estable que puede durar sin envejecer ni perder ninguno de sus elementos".

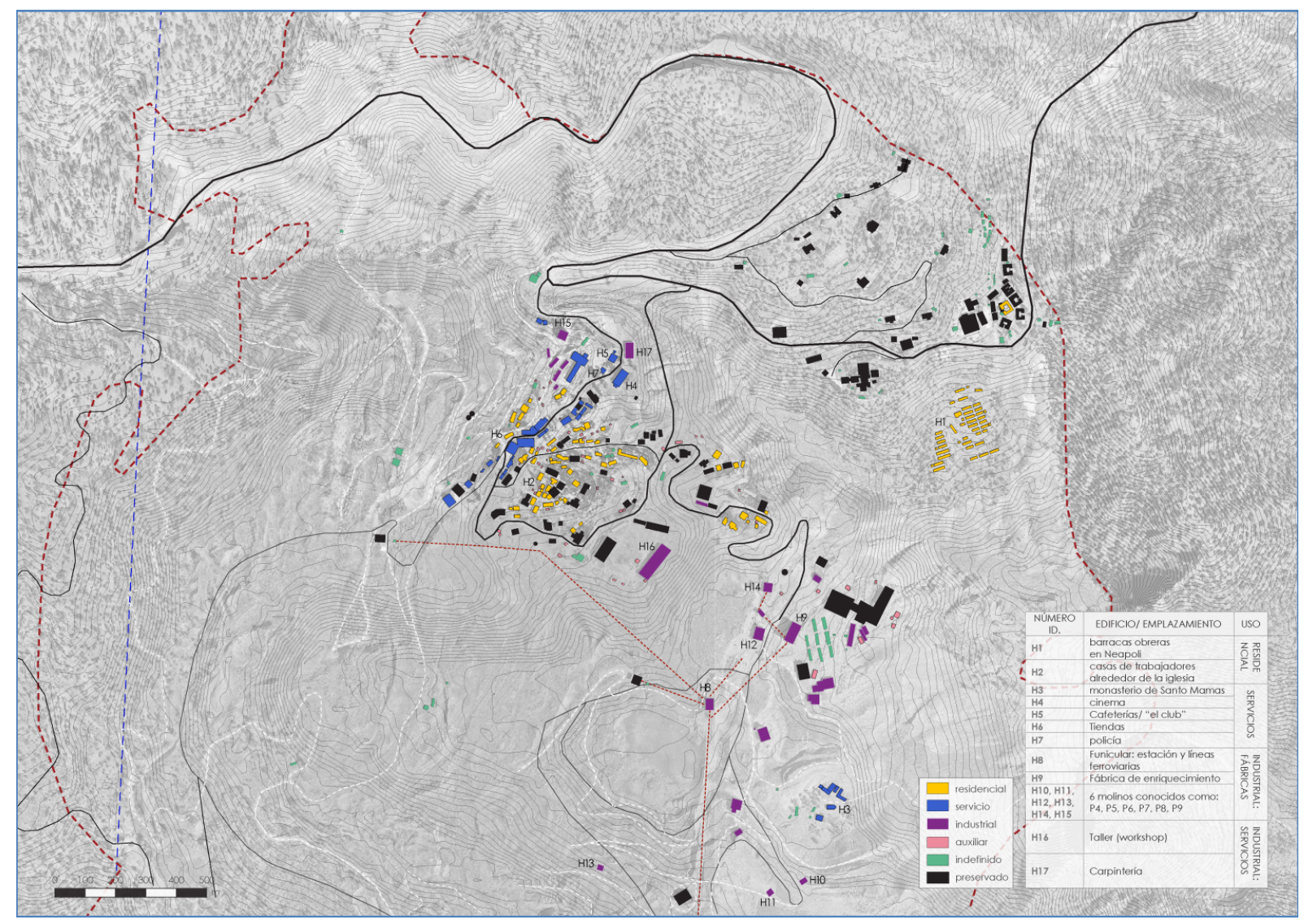

Figura 20. Edificios perdidos: Foto aérea y tabla. Fuente: Elaboración propia a partir de datos del Catastro de la República de Chipre.

Analizando la información extraída tanto de los recuerdos de la gente de Amiantos como de la bibliografía disponible y la foto aérea del 1963 he intentado identificar los hitos perdidos de la mina y ubicarlos en su marco espacial. Aún no he podido localizar el emplazamiento de todos los edificios desaparecidos por falta de información, y, por el mismo motivo, es posible que algunos de ellos no se hayan localizado con absoluta precisión. Al mismo tiempo, debido a que se realizan transformaciones en la mina mucho antes de su cierre, como resultado de la remodelación de la industria extractiva para adaptarse a los avances tecnológicos, se deduce que existen vestigios que desaparecieron en las décadas pasadas y que resulta aún más difícil identificar. Puesto que la antigua foto aérea obtenida data de 1963, la identificación de los estados previos y el grado de alteración queda en el aire. Sin embargo, considerando que la introducción de maquinaria empieza en los años 60, es posible que hasta entonces no se realizaran grandes modificaciones.

De la misma manera que los vestigios físicos, éstos también se clasifican en la tabla según su uso, y de hecho tenemos hitos perdidos de carácter industrial, residencial y de servicios, que se distinguen por motivos de identificación. Entre los mismos destaca el funicular, que en su momento daba a Amiantos un carácter singular y representativo del uso industrial, y además la fábrica de 
enriquecimiento, un edificio longitudinal de nueve plantas con una tecnología muy avanzada para su época. Cabe añadir el monasterio de Santo Mamas, un conjunto al cual la gente atribuía valores significativos como espacio de acontecimientos, donde cada año se reunía para celebrar la fiesta dedicada al Santo. Este tipo de espacios tienen una calidad comunicativa como agentes de la memoria colectiva de una comunidad, y toman su importancia por su asociación a historias de la gente, que los convierten en espacios narrativos, vinculados a la historia, la cultura y el paisaje (Sabaté et al., 2004).

En aras de la brevedad no se exponen aquí las características específicas de cada uno de los hitos perdidos. Sin embargo, es innegable que adquieren importancia por razones diversas, formando así fragmentos particulares del pasado que en su momento tenían valor como partes del conjunto. Por consiguiente, resulta imprescindible dar un enfoque adecuado a estos hitos que, con el paso de los años, han perdido su presencia física, pero siguen siendo parte de la identidad de Amiantos. Además, aunque no necesariamente todos los vestigios se reconocen como hitos, pueden aportar información valiosa debido a que aparecen entrelazados entre sí y, por ende, su identificación resulta esencial. Y como afirma Poincare, "[...] no podemos conocer las cosas totalmente, pero a través de la observación de sus relaciones internas podemos saber algo de ellas" (Domenech, 2006, p.11).
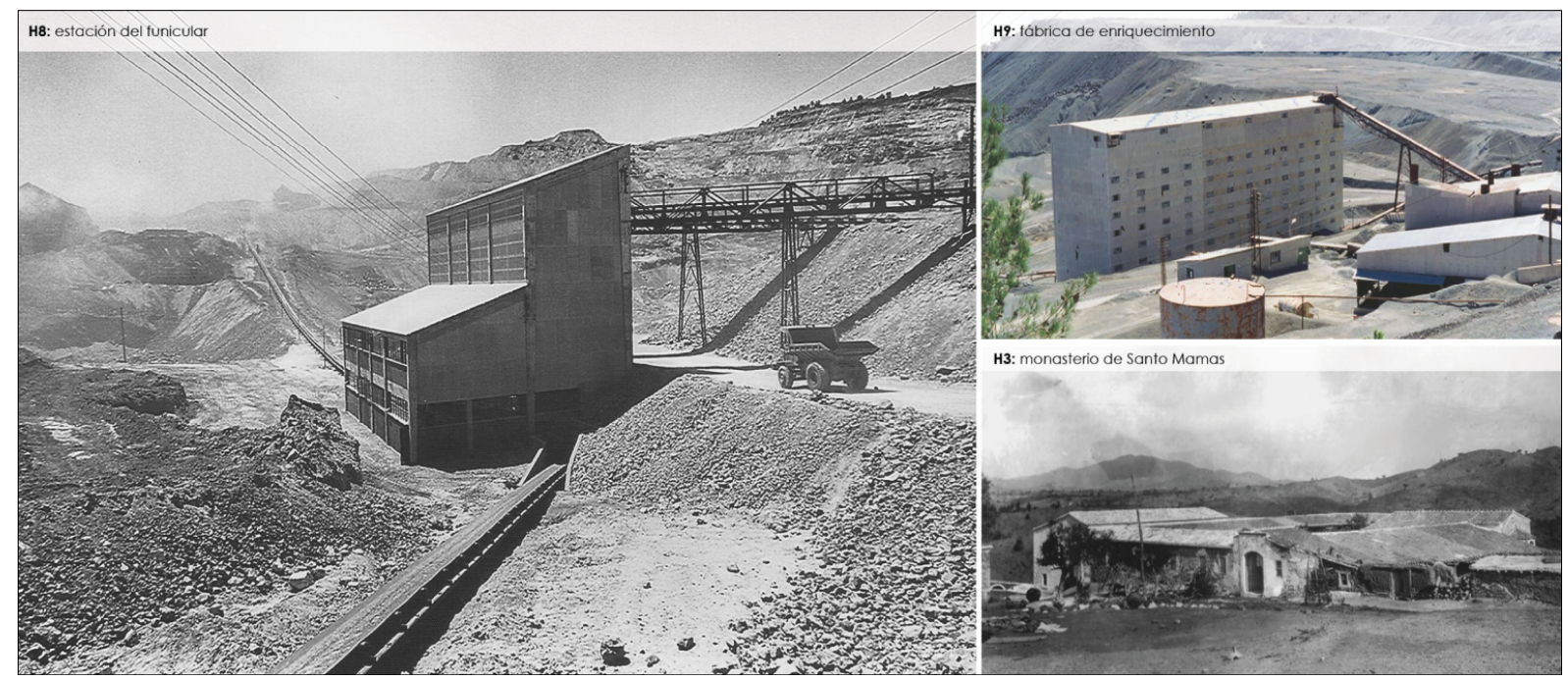

Figura 21. Edificios perdidos. Fuente: Archivo histórico del Museo Municipal Pattichion de Lemesos.

\section{Conclusiones}

"El factor determinante del patrimonio es su carácter simbólico, su capacidad para representar simbólicamente una identidad. Esto es lo que explica el cómo y por qué se movilizan recursos para conservarlo y exponerlo". Esta afirmación de Prats (1997, [2004], p.22) resume lo que se ha expuesto anteriormente, dado que estos símbolos se contextualicen en prácticas, vinculando historias y mensajes a espacios y formas (Sabaté, 2000-2004). Tras analizar los elementos constitutivos de la identidad tan diversa de Amiantos, se llega a la conclusión que se trata de un paisaje dotado de recursos suficientes para retomar un papel protagonista en su recuperación, que de momento está detenida. Algunas experiencias internacionales pueden resultar de gran utilidad para definir estrategias para reactivar la mina y definir un hilo conductor adecuado, siempre que atiendan a las necesidades de la comunidad, que levantó este valioso patrimonio. En las últimas décadas los paisajes mineros gozan de un creciente reconocimiento como legado patrimonial con capacidad para convertirse en catalizadores del desarrollo local. Los proyectos pioneros de puesta en valor de dichos paisajes y su conversión en parques patrimoniales, como Emscher Park en Alemania, Monceau-Les Mines en Francia y otros, además de los esfuerzos para su protección mediante planes, leyes y directrices, entre ellos la Belvedere Nota en Holanda y la Ley de Paisaje en Cataluña, han promovido muchas iniciativas parecidas en diversos ámbitos locales que indudablemente generan una oportunidad prometedora para la regeneración de este patrimonio amenazado, aunque todavía falta mucho que hacer para la consolidación de estrategias y conceptos. 
No hay duda que hay aún queda por recorrer un largo camino hasta garantizar la salvaguarda y reactivación de los valores de Amiantos. Aun así, acercándose a su gente, que sigue contemplando su propio pasado enterrado en las fábricas y casas, se generan esperanzas y perspectivas para un futuro cargado de memorias. Y para acentuar esta necesidad, a modo de conclusión, se retoman las palabras de José Saramago, recogidas por Sabaté (López et al., 2015), que afirman que "una sociedad que no respeta su territorio, y la huella del trabajo sobre este territorio, es una sociedad que no se respeta a sí misma".

\section{Referencias}

Amiandos, http://amiandos.com/asbestos/history/ (Consulta: 16/11/2016).

Anadysis films (productor) y Papapetrou, P (director). (2014). Amiantos: Pasado, presente y futuro.

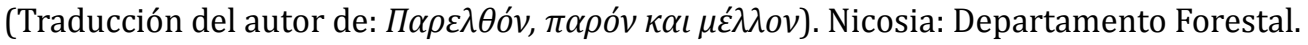

Anadysis films (productor) y Papapetrou, P (director). (2007). Memorias de mineros (Traducción del autor

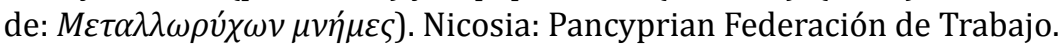

Aguilar D., M. A. (2002). Fragmentos de la memoria colectiva. Revista Athenea, Núm. 2, pp. 1-11. Publicado originalmente en (1991) Revista de Cultura Psicológica (México), 1.

Garcés F., E. (2007). Las ciudades del cobre. Santiago de Chile: Universidad Católica de Chile, Vicerrectoría de Comunicaciones y Asuntos Públicos.

Domenech R., J. (2006). La superficie y lo invisible. Patrones en la transformación de la Cuenca Minera Central Asturiana. 1890-1960. Tesis doctoral. Universitat Politècnica de Catalunya. Escola Tècnica Superior d' Arquitectura de Barcelona. Director: Sabaté, J.

Halbwachs, M. (1950). La memoria colectiva. Trad. por Sancho A., I. (2004). Zaragoza: Prensas Universitarias de Zaragoza.

International Chrysotile Association. (2015). Convenio de Róterdam. For environmental occupational health safe and responsible use. Congreso COP7 Meeting.

Loizides, C. (2013). Plan General para el desarrollo de la mina del Amiantos. Evaluación Ambiental Estratégica. Estado de Chipre. Ministerio de Agricultura, Recursos Naturales y Medio Ambiente. (traducción del autor de:

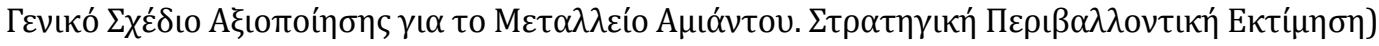

Kyrou, K. (2010). Restauración del medio ambiente en la mina de Amianto. Nicosia: Departamento de Dirección de Aguas. República de Chipre.

López M., M. I. \& Pérez B., L. (ed.). 2015. Parques mineros, ecomuseos y geoparques: estrategias de puesta en valor. Concepción: Stoq.

Marchán, C. y Sánchez, A. (2013). Consideraciones sobre el patrimonio minero desde la perspectiva de un patrimonio geológico nacional. Revista Boletim paranaense de geociencias. Vol. 70, pp. 77-86.

Pérez B., L. (2007). La mirada y la memoria: elementos de estructuración y revalorización del paisaje cultural de Lota Alto, Chile. Tesis doctoral. Universitat Politècnica de Catalunya. Escola Tècnica Superior d'Arquitectura de Barcelona. Director: Sabaté, J.

Pérez A., M. \& Sánchez P., A. (2010). Patrimonio minero: un variopinto y problemático mundo de vestigios. Revista AREAS, Núm. 29, pp. 51-59.

Prats, L. [1997, (2004)]. Antropología y patrimonio. Barcelona: Ariel.

Puche P. (2010). Amianto, una fibra mortal e invisible. Revista El Ecologista (Málaga), Núm. 66. 
Sabaté B., J. (2000-2004). Algunas pautas metodológicas en los proyectos en paisajes culturales. En: La práctica del urbanismo. Editorial Síntesis. Madrid, julio de 2011, pp. 101-124.

Sabaté B., J., Frenchman, D. J., \& Schuster, M. (ed.), (2004). Llocs amb esdeveniments = Event places. Barcelona: UPC. Departament d'Urbanisme i Ordenació del Territori: MIT. City Design and Development of Urban Studies and Planning, DL.

Sabaté B., J. (2005). De la preservación del patrimonio a la ordenación del paisaje. Revista IDENTIDADES (Barcelona), Núm. 1, pp. 15-33.

Sabaté B., J. (2001). Paisajes culturales. El patrimonio como recurso básico para un nuevo modelo de desarrollo. Revista Urban, Núm. 9, pp. 8-29.

Stavrides, S. (coord.) (2006). Memoria y experiencia del espacio. Atenas: Alexandreia. (traducción del autor

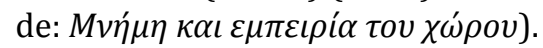

Tandy, C. (1979). Industria y paisaje. Trad. por Hernández O., J. Madrid: Instituto de Estudios de Administración Local.

Tsintides, T. (2013). Revegetación/Reforestación en la mina de Amiantos. |Conferencia sobre el proyecto

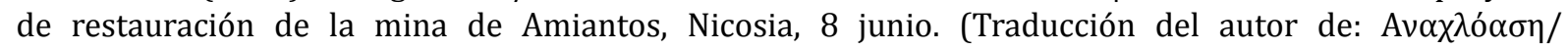

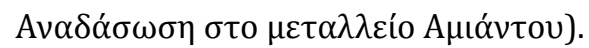

Troodos Geopark, http://www.troodos-geo.org/cgibin/hweb?-A=2\&-V=amiantos (Consulta: 10/11/2016).

Vasiliou, V. (2016). El Troodos como geoparque mundial. Revista Fileleftheros, 3 de abril. (traducción del

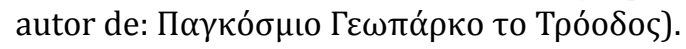

Varnava, P. (1989). Un minero recuerda. Nicosia: PEO. (Traducción del autor de: 'Evaৎ $\mu \varepsilon \tau \alpha \lambda \lambda \omega \rho v ́ \chi o \varsigma$ $\theta v \mu \alpha \dot{\tau} \tau \alpha l)$. 